\title{
Misdiagnosis as asphyxiating thoracic dystrophy and CMV-associated haemophagocytic lymphohistiocytosis in Shwachman-Diamond syndrome
}

\author{
Heidi Schaballie • Marleen Renard - Christiane Vermylen • Isabelle Scheers • \\ Nicole Revencu - Luc Regal • David Cassiman - Lieve Sevenants • Ilse Hoffman • \\ Anniek Corveleyn • Victoria Bordon • Filomeen Haerynck • Karel Allegaert • \\ Kris De Boeck • Tania Roskams • Nancy Boeckx • Xavier Bossuyt • Isabelle Meyts
}

Received: 31 July 2012 /Revised: 22 November 2012 / Accepted: 29 November 2012

(C) Springer-Verlag Berlin Heidelberg 2013

\begin{abstract}
Shwachman-Diamond syndrome (SDS) is an autosomal recessive disorder characterised by skeletal dysplasia, exocrine pancreatic insufficiency and bone marrow failure. Various other conditions, such as hepatopathy and failure to
\end{abstract}

H. Schaballie $(\bowtie) \cdot X$. Bossuyt

Department of Microbiology and Immunology,

University Hospitals Leuven, Leuven, Belgium

e-mail: heidi.schaballie@uzleuven.be

M. Renard

Department of Pediatric Hemato-Oncology,

University Hospitals Leuven, Leuven, Belgium

C. Vermylen

Department of Pediatric Hemato-Oncology,

Cliniques Universitaires St Luc,

Brussels, Belgium

I. Scheers

Department of Pediatric Gastroenterology,

Nutrition and Hepatology, Cliniques Universitaires St Luc,

Brussels, Belgium

N. Revencu

Department of Medical Genetics,

Cliniques Universitaires St Luc, Brussels, Belgium

L. Regal

Department of Metabolic Disorders,

University Hospitals Leuven, Leuven, Belgium

\section{Cassiman}

Department of Hepatology,

University Hospitals Leuven, Leuven, Belgium

\section{Sevenants}

Department of Pediatrics,

University Hospitals Leuven, Leuven, Belgium thrive have been associated with SDS. A retrospective study was conducted to describe mutations, clinical features, and the immunological profile of 11 Belgian patients with genetically confirmed diagnosis of SDS. This study confirms the existing

I. Hoffman

Department of Pediatric Gastroenterology,

Nutrition and Hepatology, University Hospitals Leuven,

Leuven, Belgium

A. Corveleyn

Center for Medical Genetics, University Hospitals Leuven,

Leuven, Belgium

V. Bordon

Department of Pediatric Hemato-Oncology,

University Hospital Ghent, Ghent, Belgium

F. Haerynck

Department of Pediatric Pulmonology and Immune Deficiencies, University Hospital Ghent, Ghent, Belgium

K. Allegaert

Department of Neonatology, University Hospitals Leuven,

Leuven, Belgium

K. De Boeck

Department of Pediatric Pulmonology,

University Hospitals Leuven, Leuven, Belgium

T. Roskams

Department of Pathology, University Hospitals Leuven,

Leuven, Belgium

N. Boeckx

Department of Laboratory Medicine, University Hospitals Leuven, Leuven, Belgium

I. Meyts

Department of Pediatrics,

Department of Microbiology and Immunology,

University Hospitals Leuven, Leuven, Belgium 
understanding of the classical features of SDS although the typical triad was present in only six out of nine fully studied patients. The following important observations are made in this cohort. Four out of eleven patients were misdiagnosed as having Asphyxiating Thoracic Dystrophy (Jeune syndrome) because of severe thoracic dystrophy. Another two patients presented with unexplained episodes of symptomatic hypoglycaemia. The immunological phenotype was heterogeneous although laboratory abnormalities were noticed in eight out of ten patients assessed. Three patients experienced a life threatening viral infection (respiratory syncytial virus, cytomegalovirus (CMV) and rotavirus). In one patient, CMV infection caused an episode of haemophagocytic lymphohistiocytosis. One patient has bronchiectasis at the age of 3 years due to recurrent respiratory tract infections. These findings strengthen the suspicion of an abnormal immune system in SDS. Liver anomalies, usually described as benign and transitory in SDS patients, were severe in two patients of the cohort. One patient developed hepatopulmonary syndrome. The findings in this national cohort of SDS patients could contribute to the prevention of misdiagnosis in the future and enable more rapid recognition of certain severe complications.

Keywords Shwachman-Diamond syndrome .

Haemophagocytosis · Asphyxiating thoracic dystrophy · Liver failure $\cdot$ Immunodeficiency

\section{Introduction}

Shwachman-Diamond syndrome (SDS) is an autosomal recessive multisystem disorder, the principal manifestations of which include exocrine pancreatic insufficiency (EPI) and bone marrow dysfunction $[3,5,16,36]$. Bone marrow dysfunction usually presents as neutropenia but may progress to myelodysplastic syndrome and acute myeloid leukaemia [10]. Much has been added to our knowledge since the original description in 1964, and the clinical phenotype was extended with skeletal dysplasia (1967) [5], hepatomegaly and elevated aminotransferase levels in childhood [37], failure to thrive [1, 16], dental anomalies [20], cognitive or behavioural problems [24, 25, 38] and skin lesions [1]. Recent growing evidence suggests immunodeficiency is also associated with SDS $[10,13]$. SDS is caused by mutations in the gene encoding Shwachman-Bodian-Diamond syndrome (SBDS) protein, which is involved in ribosomal RNA metabolism, apoptosis, and mitotic spindle stabilisation $(4,37$, OMIM *607444). The incidence of SDS was estimated approximately $1 / 76,000$ using comparison to cystic fibrosis data [17].

The aim of this study is to review the mutations, clinical presentation and immunological data in a Belgian cohort of SDS patients.

\section{Methods}

Paediatric and adult immunologists, gastro-enterologists and haematologists in all Belgian university hospitals were asked if they had genetically verified or suspected SDS cases in follow-up. Inclusion was closed in May 2011. A questionnaire was used for retrospective analyses of medical files. Based on the clinical and molecular diagnostic criteria of the recently published consensus guideline [11], only patients with a biallelic SBDS gene mutation were included since the retrospective character of the study did not allow meeting clinical diagnostic criteria. Patients who were lost to follow-up were also excluded.

Symptoms and treatment at presentation of the patient (even if SDS was not yet suspected at that time) and at latest follow-up were searched from the medical file. Data on infectious complications, culture or virology results and results of all immunological testing since birth were gathered.

The study protocol was approved by the Ethics Committee of the University Hospitals Leuven. Informed consent from all parents and adult patients was obtained to use all clinical data from the medical file anonymously.

\section{Results}

Study population

The study population and their clinical features are presented in Tables 1 and 2. Eleven patients with biallelic SBDS mutations were included. One patient with genetically confirmed diagnosis was excluded because she was lost to follow-up and another three patients had SDS phenotype but were not yet genetically confirmed. At the University Hospitals Leuven, eight patients were treated, one of which deceased before diagnosis was confirmed. Two confirmed patients were treated in the University Hospital of Ghent, one at the Université Catholique de Louvain.

There were eight male $(\mathrm{M})$ and three female $(\mathrm{F})$ patients among whom two pairs of siblings (cases - three $\mathrm{F}$ and four $\mathrm{M}$ and seven $\mathrm{M}$ and eight $\mathrm{M}$ ). The mean age of the patients at diagnosis was 2.7 years (the patient diagnosed post-mortem was not included for this calculation), ranging from 7 days to 13 years. Patients' ages at the moment of latest follow-up ranged from 4 months to 29 years, with a mean age of 6.9 years. Two out of 11 patients died: patient $4 \mathrm{M}$ died at the age of 4 days due to respiratory insufficiency caused by thoracic dystrophy; patient $11 \mathrm{M}$ died at age 3 months in the context of acute rotavirus infection with secondary multi-organ failure.

Haematological characteristics

The patients' haematological characteristics and treatment are summarised in Tables 1 and 2. 


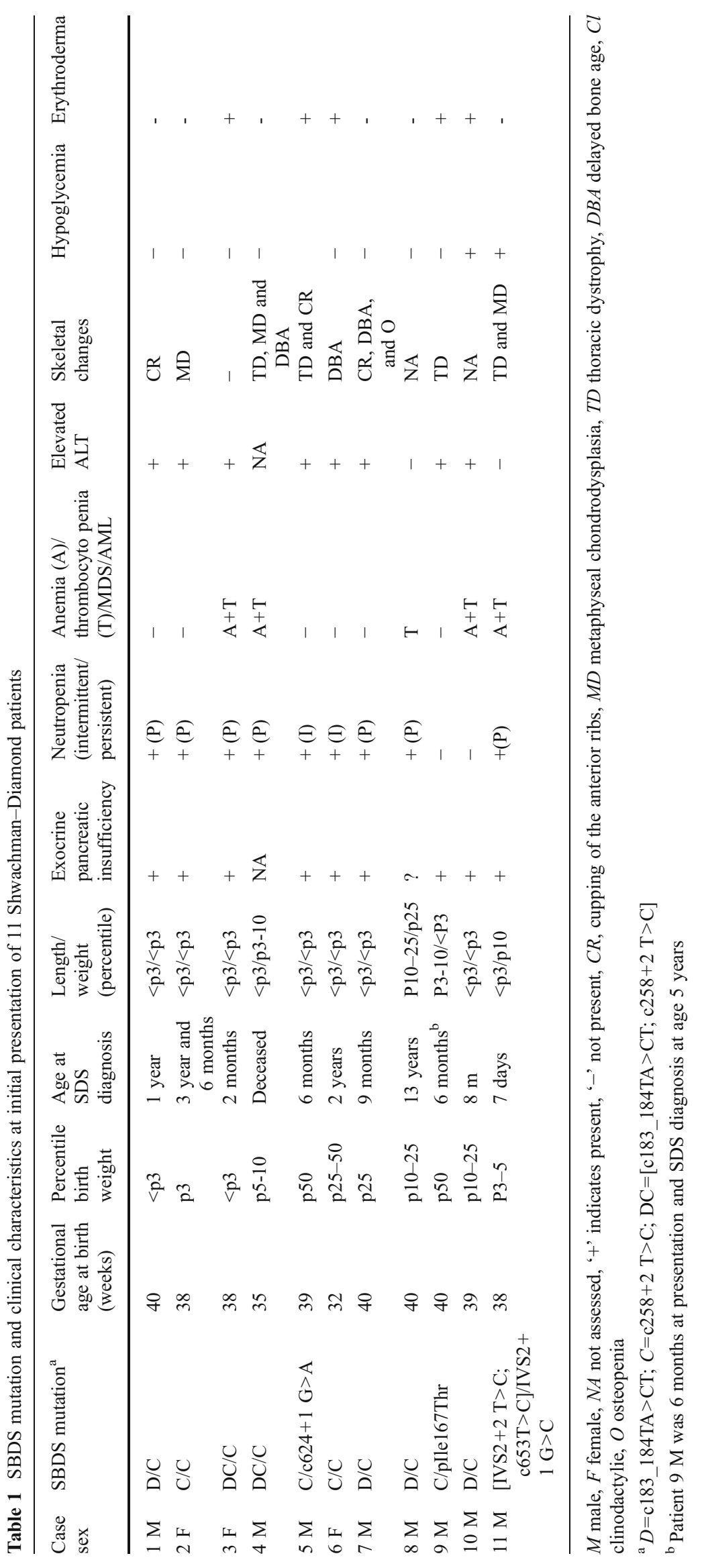




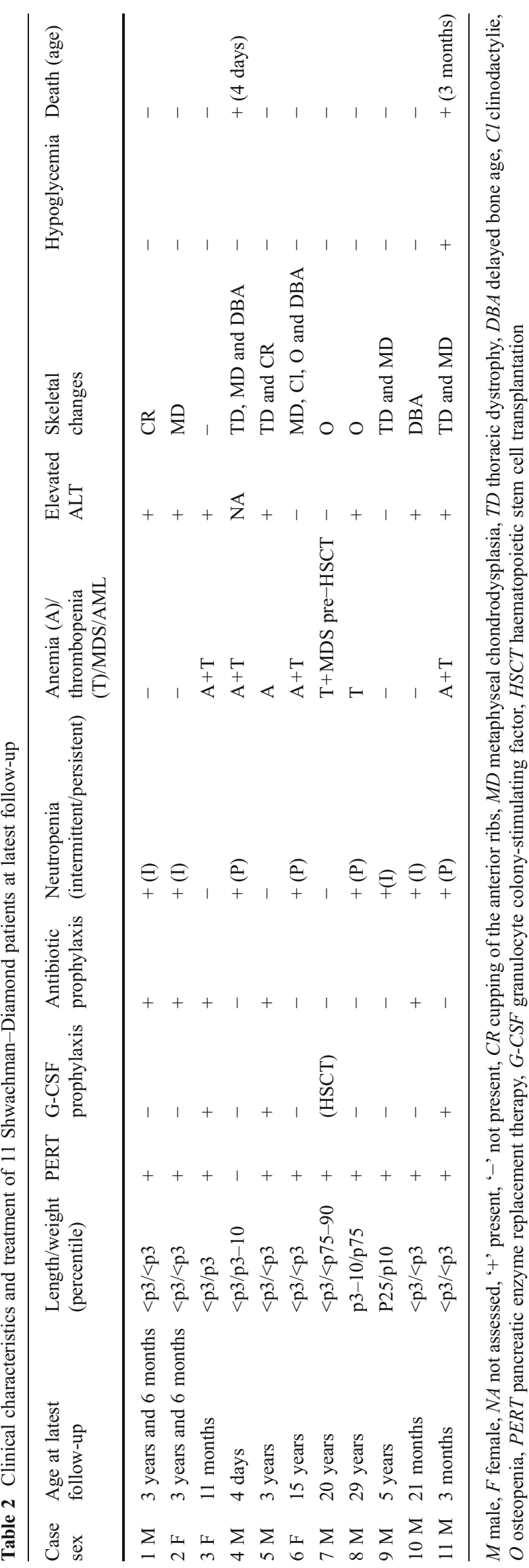

Neutropenia (neutrophil count less than $1.5^{*} 10^{9} / 1$ ) was present in 9 out of 11 patients at initial presentation. Severe neutropenia with a neutrophil count less than $0.5 * 10^{9} / 1$ was observed in 6 patients. At latest follow-up all patients without Granulocyte-Colony Stimulating Factor treatment or haematopoietic stem cell transplantation (HSCT) showed persistent or intermittent neutropenia.

All but three patients underwent bone marrow aspirations. Patient $7 \mathrm{M}$ underwent HSCT at the age of 12 years because of progression to myelodysplastic syndrome. All the other patients had bone marrow aspirates without signs of myelodysplastic syndrome or acute myeloid leukaemia.

Patient $10 \mathrm{M}$ suffered an episode of haemophagocytic lymphohistiocytosis (HLH) during cytomegalovirus (CMV) infection. He presented with fever and cholestatic liver failure. Blood analyses showed anemia and thrombocytopenia, fibrinogen was less than $0.80 \mathrm{~g} / 1$, ferritin was as high as $1,370 \mu \mathrm{g} / \mathrm{l}$, hypertriglyceridemia was mild and serum CD25 was not measured. Haemophagocytosis was confirmed on bone marrow and liver biopsy (Fig. 1).

Infectious complications and immunological abnormalities

Three patients suffered from a life threatening viral infection. Patient $9 \mathrm{M}$ had respiratory syncytial virus (RSV) bronchiolitis with severe clinical course. Patient $10 \mathrm{M}$ showed a clinical picture of cholestatic hepatitis, HLH and excreted CMV at the same time. A rotavirus infection led to multi-organ failure and death in patient $11 \mathrm{M}$ at the age of 3 months. Immunological profile of patients $9 \mathrm{M}$ and $11 \mathrm{M}$ were not extensively examined. Natural killer cell function was tested in patient $10 \mathrm{M}$ because of HLH and was normal. Natural killer cell number was abnormal in two of seven patients but not in patient $10 \mathrm{M}$. Patient $8 \mathrm{M}$ experienced frequently recurring ocular herpesvirus infection.

Nine patients had a history of frequent and/or serious bacterial infections. Skin infections and sepsis were most common (Table 3). Sepsis occurred mostly in the first years of life. Patient $5 \mathrm{M}$ suffered from severe recurrent respiratory tract infections since birth and had bronchiectasis on chest CT scan at the age of 3 years. This patient had a very low antibody response to tetanus toxoid and no response to pneumococcal unconjugated vaccine (PPV23). Five patients were receiving antibiotic prophylaxis at latest follow-up with apparent beneficial effect on infection rate.

The occurrence of immunological abnormalities is summarised in Table 4.

Hepatic abnormalities

Serum aminotransferase levels were elevated on at least one occasion in all patients studied (Tables 1 and 2). Two patients had severe hepatic manifestations. Patient $10 \mathrm{M}$ presented at the age of 8 months with cholestatic liver failure, requiring 


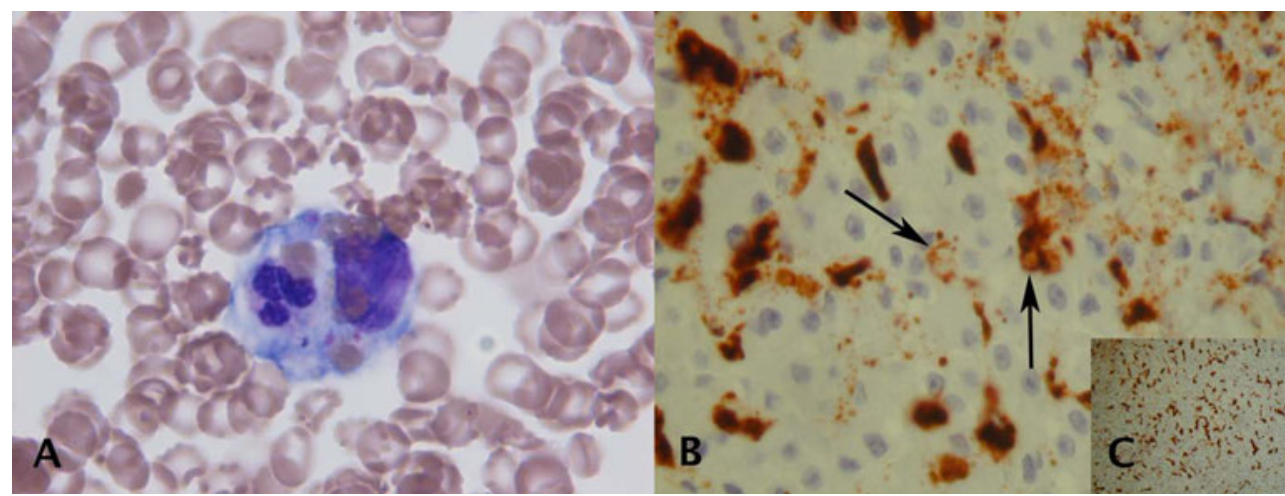

Fig. 1 Haemophagocytosis on bone marrow aspirate and liver biopsy of patient $10 \mathrm{M}$. a May-Grünwald Giemsa staining on bone marrow aspirate $(\times 1,000)$. Macrophage with internalised neutrophil, red blood

admission to the intensive care unit. Liver biopsy showed signs of chronic cholestasis, periportal fibrosis, steatosis and haemophagocytosis (Fig. 1). Shortly after the biopsy anti-CMV IgM and IgG antibodies were detected in the blood. Blood PCR on CMV showed little copies $(<500 / \mathrm{ml})$ of CMV but urine culture was also positive. On the biopsy specimen CMV PCR was not performed. Five days after the start of ganciclovir therapy the liver function recovered. The patient made a full recovery.

Patient $6 \mathrm{~F}$ had a first liver biopsy at the age of 2 years in the context of persistent elevated serum aminotransferases and intermittent disturbance of cholestatic enzymes. There were no symptoms of cholestasis. The biopsy showed mild periportal fibrosis and signs of mild chronic cholestasis. A second biopsy at the age of 15 years showed an increase of fibrosis and severe cholestasis. Recently, a hepatopulmonary syndrome was diagnosed by catheterisation and ventilation/ perfusion scan, following presentation with hypoxemia and low exercise tolerance. She is now being considered for a liver transplantation.

Table 3 Infections in the studied SDS population

${ }^{\mathrm{a}}$ Number of patients who suffered at least once from the mentioned infection cells and platelets. b Liver specimen immunostained for CD68 $(\times 400)$. Macrophages (brown stain) with phagocyted blood cells (arrowheads). c Numerous macrophages on liver specimen stained for CD68 $(\times 100)$

\section{Skeletal abnormalities}

Four Belgian SDS patients had thoracic dystrophy. Patient $11 \mathrm{M}$ died due to respiratory failure caused by severe thoracic dystrophy (Fig. 2). The diagnosis of SDS was made retrospectively after the diagnosis of SDS in a sibling. Thoracic dystrophy led to a preliminary diagnosis of Jeune syndrome or asphyxiating thoracic dystrophy (ATD) in all four patients. Skeletal abnormalities were reported in all but one patient during the course of follow-up (Tables 1 and 2). At initial presentation skeletal abnormalities were detected in eight of nine patients. Only three of nine patients had metaphyseal dysostosis. At latest follow-up 5 of 11 patients had metaphyseal dysostosis. In three patients, cupping of the anterior ribs was seen. Assessment of bone age using the Greulich-Pyle standards indicated retardation in three patients. In three patients (aged 15, 20 and 29 years), dualenergy X-ray absorpsiometry was performed for analysis of bone mineral content. Patient $6 \mathrm{~F}$ had a $Z$-score for the

\begin{tabular}{|c|c|c|c|}
\hline \multirow[t]{11}{*}{ ied SDS population } & Infection & Cases $^{\mathrm{a}}$ & Micro-organism \\
\hline & Recurrent respiratory tract infection & $7 / 11$ & \\
\hline & Cellulitis/skin infection & $5 / 11$ & $\begin{array}{l}\text { Staphylococcus aureus, group G Streptococcus, } \\
\text { Stenotrophomonas maltophilia, Enterobacter cloacae, } \\
\text { Candida sp., Escherichia coli, coagulase-negative } \\
\text { Staphylococcus sp., Klebsiella sp., and Enterococcus sp. }\end{array}$ \\
\hline & Septicemia & $4 / 11$ & $\begin{array}{l}\text { Corynebacterium sp., Staphylococcus epidermidis, } \\
\text { Streptococcus viridians }\end{array}$ \\
\hline & Pneumonia & $3 / 11$ & RSV, CMV and unidentified \\
\hline & Acute otitis media & $3 / 11$ & \\
\hline & Gastro-enteritis & $3 / 11$ & Clostridium sp., Salmonella sp. and rotavirus \\
\hline & Abscess & $2 / 11$ & Pseudomonas aeruginosa \\
\hline & Hepatitis & $1 / 11$ & $\mathrm{CMV}$ \\
\hline & Pyelonephritis & $2 / 11$ & E. coli and Proteus mirabilis \\
\hline & Recurrent gastrostomy infection & $1 / 11$ & \\
\hline \multirow{2}{*}{$\begin{array}{l}{ }^{a} \text { Number of patients who suf- } \\
\text { fered at least once from the } \\
\text { mentioned infection }\end{array}$} & Mastoiditis & $1 / 11$ & \\
\hline & Keratitis & $1 / 11$ & Herpes \\
\hline
\end{tabular}


Table 4 Immunological abnormalities in the Belgian cohort

\begin{tabular}{lc}
\hline Immunological deficiency & $\begin{array}{l}\text { Positive cases/cases } \\
\text { tested }\end{array}$ \\
\hline Neutropenia & $11 / 11$ \\
Low total lymphocyte count & $0 / 11$ \\
Low CD19+ B cell count & $3 / 8$ \\
Low CD3+ T cell count & $0 / 8$ \\
Low circulating natural killer cells & $2 / 6$ \\
Low IgG & $0 / 9$ \\
Low IgA & $1 / 9$ \\
Low IgM & $4 / 9$ \\
Abnormal lymphocyte response to Con A, & $0 / 3$ \\
PWM or PHA & $2 / 3$ \\
Abnormal lymphocyte response to tetanus toxin & $2 / 4$ \\
Abnormal pneumococcal polysaccharide & \\
antibody response & $3 / 4$ \\
Abnormal iso-hemagglutinine titer & \\
Neutrophil chemotaxis defect & $4 / 4$ \\
\hline
\end{tabular}

${ }^{\text {a }}$ Anti-A and anti-B isohaemagglutinin levels were low in three patients with blood type $\mathrm{O}$

spine of -3.7. Patient $7 \mathrm{M}$ and $8 \mathrm{M}$ had a $T$-score for the spine of -1.9 and -2.4 , respectively. Miscellaneous findings included clinodactyly (6 F), hypoplastic 12th rib (1 M) and forked 6th rib (5 M).

\section{Pancreatic function}

Exocrine pancreatic function was assessed in various ways. Six patients had reduced fecal elastase concentration with or without another abnormal test. In patients $6 \mathrm{~F}$ and $7 \mathrm{M}$, EPI was diagnosed using a pancreatic stimulation test. One

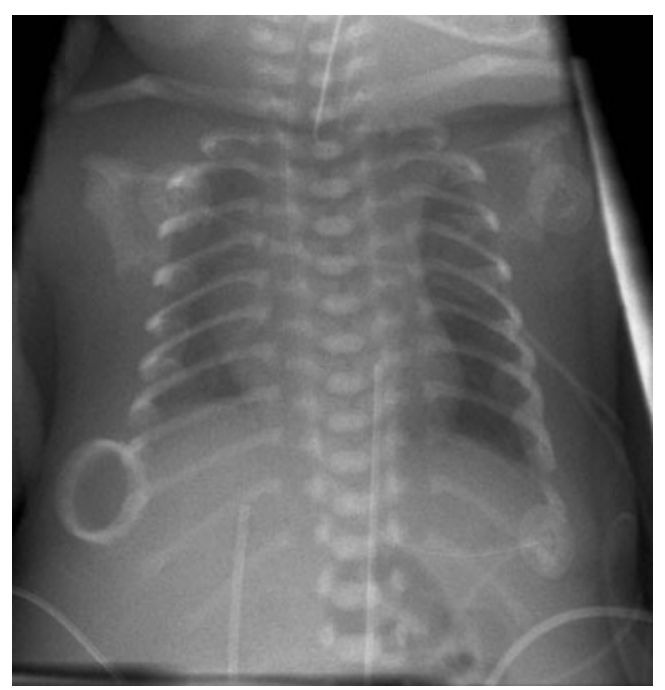

Fig. 2 Narrow thorax, short ribs and elevated clavicles on chest X-ray of patient $4 \mathrm{M}$ patient was on pancreatic enzyme replacement therapy (PERT) because of abdominal complaints and a hyperchogenic pancreas on echography without further diagnostic testing. In one patient the diagnostic method is unknown. According to the consensus for SDS diagnosis [11] pancreatic dysfunction was present in eight of ten patients and possible in two more patients at the time of presentation (Table 1). In patient $4 \mathrm{M}$, pancreatic function was not analysed, he was on total parenteral nutrition until he deceased. At the moment of latest follow-up, all but patient 4 $M$ were on PERT (Table 2). Repeated tests of exocrine pancreatic function were lacking.

In none of the patients there was evidence of endocrine pancreatic insufficiency.

Patient $10 \mathrm{M}$ showed two episodes of symptomatic hypoglycaemia (convulsions) at the age of 8 and 11 months. Patient $11 \mathrm{M}$ had recurrent episodes of symptomatic hypoglycaemia from birth till death at age 3 months. No endocrinological abnormalities could be found and metabolic investigations were normal. The nutritional status of both patients was very poor at the time of events.

\section{Other features}

One or more episodes of diffuse erythroderma were reported in five patients. One patient suffered from multiple episodes of telogen effluvium. Because of low serum Zinc levels this was treated with oral zinc suppletion. Dental data were available from four patients, three having dental complications. One patient had dysplastic enamel, one patient had a dental abscess and one patient had a retained deciduous tooth.

Eight patients had echocardiography performed, which were all normal. Apart from one patient with renal tubular acidosis type 1 , no renal abnormalities were reported.

The two adult patients both reported chronic arthralgia without biochemical or clinical evidence of inflammation. Six out of ten patients showed a developmental delay. Behavioural problems were stated in the medical file of all adolescent and adult patients. None of the patients lived independently.

\section{Discussion}

In this small cohort of patients with SDS, several observations are made that elucidate the varying ways in which this condition presents. From a genetic point of view the study population is representative of the Caucasian SDS population since the commonest SBDS mutations are found in $77 \%$ of alleles (Table 1) [4]. Given the estimated incidence of SDS, there should be one or two new diagnoses of SDS in Belgium every year. It is unknown whether other cases were 
missed or misdiagnosed. The main limitation to our study is the retrospective character. However, our findings could contribute to earlier diagnosis and treatment.

From the results of this study one could strongly suspect immunodeficiency in SDS. SDS-associated immunodeficiency has been addressed in several publications, while the mechanisms of immunodeficiency are yet unknown. Patients with SDS seem prone to recurrent infections even with protective neutrophil counts and to infections with both viral as well as bacterial pathogens. However, infectious complications of SDS have not been extensively reviewed in the past. In this cohort respiratory tract infections, skin infections or abcesses and sepsis were the most common bacterial infections (Table 3). Pathogens are listed in Table 3. Our findings are consistent with the most recent literature review on infectious complications in SDS [18].

Strikingly, three viral infections with a severe course were noted in this small cohort: RSV infection, CMV hepatitis and rotavirus infection. One patient suffered from recurrent ocular herpes infection. Viral infections with a severe course have been described in earlier case series, i.e. congenitally acquired parvovirus B19 and complicated measles infection [18]. Cipolli et al. described a girl of 7 months who died of respiratory insufficiency probably caused by CMV [6].

Three patients suffered from both severe viral and bacterial infections. The combined susceptibility to viral and bacterial infections has led to the suspicion of other immunological defects besides neutropenia and neutrophil chemotaxis defect in SDS. Dror et al. conducted a prospective study in 11 SDS patients which found a variable pattern of immune deficiencies [13]. Another retrospective study of immunological function in 13 SDS patients confirmed a heterogeneous but significant immune deficiency (Eckstein and Myers, oral communication, 2011 International Symposium on SDS). It reported on decreased natural killer cell function, low immunoglobulin $\mathrm{M}$ and decreased cytotoxic $\mathrm{T}$ cell function next to previously reported defects in chemotaxis and $\mathrm{T}$ cell proliferative responses. In 11 Belgian SDS patients, neutropenia and neutrophil chemotaxis defects were the most consistent immunological characteristics. Other abnormalities of immune function were low B cell count (three of eight patients), low IgA (one of nine), low IgM (four of nine), abnormal antigen or vaccine response (two of four) and low number of circulating NK cells (two of six). One patient experienced $\mathrm{HLH}$, according to the HLH-2004 trial definition [21]. This is a syndrome of pathologic immune activation characterised by clinical signs and symptoms of extreme inflammation. Different genetic defects have been identified in HLH, all leading to a phenotype with impaired cytotoxic function by NK and T cells. The syndrome is often triggered by a viral infection, malignancy or rheumatologic disorders. [21, 32] To our knowledge, HLH has not yet been described before in SDS. Eckstein et al. provided evidence of disturbed natural killer cell function in five of ten SDS patients and cytotoxic T cell function was reduced in two of three children tested (Eckstein and Myers, unpublished data). There was no cytotoxic defect identified in our patient with HLH.

Recurrent respiratory tract infections are common in SDS $[1,16]$. In analogy with other immunodeficiency syndromes pulmonary complications are to be expected. Patients with common variable immunodeficiency often present with recurrent respiratory tract infections and bronchiectasis and some cases of common variable immunodeficiency turned out to be caused by SBDS mutations [26]. However, chronic lung disease has never been described in SDS patients. We found bronchiectasis in one 3-year-old patient $(5 \mathrm{M})$ with low pneumococcal antibody response and suspect it to be more frequent in the SDS population. The other patient with low pneumococcal antibody response has a history of pneumonia but no evidence of bronchiectasis so far.

The clinical infection pattern with recurrent respiratory tract infections, life threatening viral infections and haemophagocytosis raises a strong suspicion of immunodeficiency in SDS. The variable pattern of immunological abnormalities further supports this. Due to the retrospective character of the study, some core immunological data are missing and it is hard to link the clinical problems to the immunological defects. Prospective study of infections, immune dysregulation syndromes and immunological abnormalities in SDS patients is necessary.

Another striking finding is the frequent misdiagnosis of SDS as ATD. In this small cohort, thoracic dystrophy led to presumed diagnosis of ATD in four patients, one of which died shortly after birth due to respiratory failure. Mäkitie showed that during the first 2 years of life chest radiographs are universally abnormal with cupping and irregularity of the anterior ribs [30]. Thoracic dystrophy occurs in 40-80\% of SDS cases [12]. There are several case reports of children who were initially diagnosed with ATD [24] but the proportion of misdiagnosis in the current study (4 of 11) is marked.

ATD is a rare autosomal recessive skeletal dysplasia characterised by a constricted thoracic cage, short-limbed short stature and multi organ involvement. It often led to death in the neonatal period from asphyxia but patients are now increasingly surviving because of improved intensive supportive care. Affected individuals who survive early childhood usually develop progressive renal failure. Hepatic fibrosis and pancreatic cystic disease have also been described [7, 24]. (OMIM*208500). The diagnosis in the prenatal or neonatal period is based on clinical and radiological findings. Two causative genes have recently been identified and several loci have been implicated in those patients lacking mutations of these genes. Pancreatic insufficiency is said to occur in both diseases however all cases 
described in literature as ATD with pancreatic insufficiency seem, with current knowledge, to have been SDS cases [7, 23, 24]. Every case of thoracic dystrophy warrants thorough familial history, complete blood count, pancreatic testing and in doubt SBDS genotyping. Especially in cases of neonatal death due to thoracic dystrophy, suspicion of SDS and analyses of the SBDS gene are important for genetic counselling of the parents.

Liver abnormalities consisting of elevated liver enzyme levels and/or hepatomegaly are frequently observed in SDS patients but often normalise by the age of 5 years [37]. Although fatal liver failure after induction for HSCT has been described, the overall prognosis of SDS-associated hepatopathy is considered benign $[33,37,40]$. However two patients of the Belgian cohort experienced an episode of severe cholestatic liver failure: in one patient this was during CMV infection, in the other patient a cause remains unknown. One could speculate that SBDS-deficient cells react differently from normal hepatocytes in stress situations such as CMV infection or induction for HSCT. Since CMV infection was associated with haemophagocytic lymphohistiocytosis, immunodeficiency or immune dysregulation might be a contributing factor in the development of liver failure in this patient. The second patient now suffers from chronic liver failure with liver fibrosis and hepatopulmonary syndrome. Hepatopulmonary syndrome has never been described before in SDS. Any decline in exercise capacity or the new occurrence of cyanosis should be meticulously investigated, especially in patients with a history of severe hepatopathy. Further longitudinal study of hepatic abnormalities is crucial to define if the prognosis of SDSassociated hepatopathy is as benign as now assumed.

Our findings stress the possibility of symptomatic hypoglycaemia as a presenting or early feature of SDS since this was seen in two patients of the cohort. Two other cases of SDS and symptomatic hypoglycaemia have been reported $[2,28]$. In both patients, hypoglycaemia was one of the presenting symptoms. Our patients also experienced hypoglycaemia before or within a month after initiation of pancreatic enzyme replacement therapy. Despite extensive laboratory analysis for endocrinological or metabolic abnormalities, aetiology of hypoglycaemia remained unclear in all patients. Malnutrition and liver failure may have been contributing factors. Interestingly, diabetes mellitus has also been reported in patients with SDS [14, 15, 22, 34]. The biological mechanism underlying the disturbance of the glucose metabolism in SDS remains unclear.

Classically, SDS is characterised by a triad of EPI, skeletal dysplasia and neutropenia. In our cohort, SDS triad was present in only 6 out of 9 fully studied patients upon presentation. EPI is a consistent finding at diagnosis in all patients of the cohort. EPI with steatorrhea is reported in $90-100 \%$ of SDS patients at the age of 1 year [19]. Nevertheless the pancreatic condition improves over time in at least half of the patients $[5,29]$. Characteristic skeletal changes are present in all patients with SDS but their severity and localisation varies with age [30]. In this cohort, all but one patient showed skeletal changes. The characteristic changes are: delayed appearance of secondary ossification centres, metaphyseal dysostosis and generalised osteopenia. All patients in the cohort with bone mineral density measurements showed osteopenia. Study of bone mineral density, bone biopsies and vitamin $\mathrm{D}$ and $\mathrm{K}$ status in SDS patients suggest a primary defect in bone metabolism [34, 39]. Our haematological findings are in agreement with established knowledge from larger cohorts [8-10].

Furthermore, we provide a detailed description of miscellaneous findings in SDS. In our centre, five patients experienced at least one episode with diffuse erythoderma, usually before the age of one year and prior to diagnosis and treatment of EPI. Ichtyotic skin rash or varying degrees of eczema have frequently been observed among SDS patients in different case series [1,31]. Nezelof and Watchi suggested the possibility of hypovitaminosis A as a cause of the skin manifestations [31]. Primary immunodeficiency is a known cause of severe neonatal erythroderma. It can be hypothesised that immunodeficiency is a contributing factor in skin problems in SDS. Dental or oral problems are frequent findings [20]. Heart, kidneys, eyes, endocrine pancreas and the palate are infrequently involved [1, 12, 16, 27, 35]. Developmental and/or behavioural problems were noted in all Belgian patients. Children with SDS indeed display behavioural problems and weaker overall intellectual reasoning, attention and academic achievement, as well as a lower functional level of independence [24, 25].

\section{Conclusions}

This cohort study, although small, highlights heterogeneity of the phenotype of SDS. First, awareness of thoracic dystrophy as a common presenting feature of SDS is crucial to avoid misdiagnosis. Second, symptomatic, yet unexplained, hypoglycaemia can be a sign of SDS. Third, viral infections can have a severe course in SDS. Moreover, primo CMV infection was associated with cholestatic liver failure and HLH in one patient. The nature of the immunodeficiency in SDS varies but certainly merits further attention. However, prospective research is crucial to further investigate the immunological features of SDS.

Acknowledgements We thank all patients and their parents for their cooperation. IM is supported by a KOF grant of the Katholieke Universiteit Leuven and by a GOA of the Katholieke Universiteit Leuven and by the Jeffrey Modell Foundation. KA is supported by the Fund for Scientific Research, Flanders (Belgium) (FWO Vlaanderen) by a Fundamental Clinical Investigatorship $(1800209 \mathrm{~N})$. LR is supported by the Fund for Scientific Research, Flanders (Belgium) (FWO Vlaanderen). IS is supported by an Institut de Recherche Clinique Grant of the Universite Catholique de Louvain. 
Competing interests The authors declare that they have no competing interests.

\section{References}

1. Aggett PJ, Cavanagh NP, Matthew DJ, Pincott JR, Sutcliffe J, Harries JT (1980) Shwachman's syndrome. A review of 21 cases. Arch Dis Child 55(Suppl 5):331-347

2. Albrecht LA, Gorges SW, Styne DM, Bremer AA (2009) Shwachman-Diamond syndrome presenting as hypoglycemia. Clin Pediatr (Phila) 48(Suppl 2):212-214

3. Bodian M, Sheldon W, Lightwood R (1964) Congenital hypoplasia of the exocrine pancreas. Acta Paediatr 53:282-293

4. Boocock GRB, Morrison JA, Popovic M, Richards N, Ellis L, Durie PR, Rommens JM (2003) Mutations in SBDS are associated with Shwachman-Diamond syndrome. Nat Genet 33(Suppl 1):97101

5. Burke V, Colebatch JH, Anderson CM, Simons MJ (1967) Association of pancreatic insufficiency and chronic neutropenia in childhood. Arch Dis Child 42(Suppl 222):147-157

6. Cipolli M, D'Orazio C, Delmarco A, Marchesini C, Miano A, Mastella G (1999) Shwachman's syndrome: pathomorphosis and long-term outcome. J Pediatr Gastroenterol Nutr 29(Suppl 3):265272

7. de Vries J, Yntema JL, van Die CE, Crama N, Cornelissen EAM, Hamel BCJ (2010) Jeune syndrome: description of 13 cases and a proposal for follow-up protocol. Eur J Pediatr 169(Suppl 1):77-88

8. Donadieu J, Fenneteau O, Beaupain B, Beaufils S, Bellanger F, Mahlaoui N, Lambilliotte A, Aladjidi N, Bertrand Y, Mialou V, Perot C, Michel G, Fouyssac F, Paillard C, Gandemer V, Boutard P, Schmitz J, Morali A, Leblanc T, Bellanné-Chantelot C, the associated investigators of the French Severe Chronic Neutropenia Registry (2012) Classification of and risk factors for hematologic complications in a French national cohort of 102 patients with Shwachman-Diamond syndrome. Haematologica 97(9):13121319

9. Donadieu J, Leblanc T, Bader Meunier B, Barkaoui M, Fenneteau O, Bertrand Y, Maier-Redelsperger M, Micheau M, Stephan JL, Phillipe N, Bordigoni P, Babin-Boilletot A, Bensaid P, Manel AM, Vilmer E, Thuret I, Blanche S, Gluckman E, Fischer A, Mechinaud F, Joly B, Lamy T, Hermine O, Cassinat B, Bellanné-Chantelot C, Chomienne C (2005) Analysis of risk factors for myelodysplasias, leukemias and death from infection among patients with congenital neutropenia. Experience of the French severe chronic neutropenia study group. Haematologica 90(Suppl 1):45-53

10. Dror Y (2005) Shwachman-Diamond syndrome. Pediatr Blood Cancer 45(Suppl 7):892-901

11. Dror Y, Donadieu J, Koglmeier J, Dodge J, Toiviainen-Salo S, Mäkitie O, Kerr E, Zeidler C, Shimamura A, Shah N, Cipolli M, Kuijpers T, Durie P, Rommens J, Siderius L, Liu JM (2011) Draft consensus guidelines for diagnosis and treatment of ShwachmanDiamond syndrome. Ann NY Acad Sci 1242:40-55

12. Dror Y, Freedman MH (2002) Shwachman-Diamond syndrome. Br J Haematol 118(Suppl 3):701-713

13. Dror Y, Ginzberg H, Dalal I, Cherepanov V, Downey G, Durie P, Roifman CM, Freedman MH (2001) Immune function in patients with Shwachman-Diamond syndrome. Br J Haematol 114(Suppl 3):712-717

14. Filippi L, Tronchin M, Pezzati M, Chiti G, Dani C, Vichi GF, Rubaltelli FF (2002) Shwachman syndrome in a preterm newborn associated with transient diabetes mellitus. J Pediatr Gastroenterol Nutr 34(Suppl 2):219-223
15. Gana S, Sainati L, Frau MR, Monciotti C, Poli F, Cannioto Z, Comelli M, Danesino C, Minelli A (2011) Shwachman-Diamond syndrome and type 1 diabetes mellitus: more than a chance association? Exp Clin Endocrinol Diabetes 119(Suppl 10):610-612

16. Ginzberg H, Shin J, Ellis L, Morrison J, Ip W, Dror Y, Freedman M, Heitlinger LA, Belt MA, Corey M, Rommens JM, Durie PR (1999) Shwachman syndrome: phenotypic manifestations of sibling sets and isolated cases in a large patient cohort are similar. J Pediatr 135(Suppl 1):81-88

17. Goobie S, Popovic M, Morrison J, Ellis L, Ginzberg H, Boocock GR, Ehtesham N, Bétard C, Brewer CG, Roslin NM, Hudson TJ, Morgan K, Fujiwara TM, Durie PR, Rommens JM (2001) Shwachman-Diamond syndrome with exocrine pancreatic dysfunction and bone marrow failure maps to the centromeric region of chromosome 7. Am J Hum Genet 68(Suppl 4):1048-1054

18. Grinspan ZM, Pikora CA (2005) Infections in patients with Shwachman-Diamond syndrome. Pediatr Infect Dis J 24(Suppl 2):179-181

19. Hall GW, Dale P, Dodge JA (2006) Shwachman-Diamond syndrome: UK perspective. Arch Dis Child 91(Suppl 6):521-524

20. Ho W, Cheretakis C, Durie P, Kulkarni G, Glogauer M (2007) Prevalence of oral diseases in Shwachman-Diamond syndrome. Spec Care Dentist 27(Suppl 2):52-58

21. Jordan MB, Allen CE, Weitzman S, Filipovich AH, McClain KL (2011) How I treat hemophagocytic lymphohistiocytosis. Blood 118(15):4041-4052

22. Kamoda T, Saito T, Kinugasa H, Iwasaki N, Sumazaki R, Mouri Y, Izumi I, Hirano T, Matsui A (2005) A case of Shwachman-Diamond syndrome presenting with diabetes from early infancy. Diabetes Care 28(Suppl 6):1508-1509

23. Karjoo M, Koop CE, Cornfeld D, Holtzapple PG (1973) Pancreatic exocrine enzyme deficiency associated with asphyxiating thoracic dystrophy. Arch Dis Child 48(Suppl 2):143-146

24. Keogh SJ, McKee S, Smithson SF, Grier D, Steward CG (2012) Shwachman-Diamond syndrome: a complex case demonstrating the potential for misdiagnosis as asphyxiating thoracic dystrophy (Jeune syndrome). BMC Pediatr 12:48

25. Kerr EN, Ellis L, Dupuis A, Rommens JM, Durie PR (2010) The behavioral phenotype of school-age children with ShwachmanDiamond syndrome indicates neurocognitive dysfunction with loss of Shwachman-Bodian-Diamond syndrome gene function. J Pediatr 156(Suppl 3):433-438

26. Khan S, Hinks J, Shorto J, Schwarz MJ, Sewell WAC (2008) Some cases of common variable immunodeficiency may be due to a mutation in the SBDS gene of Shwachman-Diamond syndrome. Clin Exp Immunol 151(Suppl 3):448-454

27. Kopel L, Gutierrez PS, Lage SG (2011) Dilated cardiomyopathy in a case of Shwachman-Diamond syndrome. Cardiol Young 21 (Suppl 5):588-590

28. Kuijpers TW, Nannenberg E, Alders M, Bredius R, Hennekam RCM (2004) Congenital aplastic anemia caused by mutations in the SBDS gene: a rare presentation of Shwachman-Diamond syndrome. Pediatrics 114(Suppl 3):e387-e391

29. Mack DR, Forstner GG, Wilschanski M, Freedman MH, Durie PR (1996) Shwachman syndrome: exocrine pancreatic dysfunction and variable phenotypic expression. Gastroenterology 111(Suppl 6):1593-1602

30. Mäkitie O, Ellis L, Durie PR, Morrison JA, Sochett EB, Rommens JM, Cole WG (2004) Skeletal phenotype in patients with ShwachmanDiamond syndrome and mutations in SBDS. Clin Genet 65(Suppl 2):101-112

31. Nezelof C, Watchi M (1961) Lipomatous congenital hypoplasia of the exocrine pancreas in children. ( 2 cases and review of the literature). Arch Fr Pediatr 18:1135-1172

32. Pachlopnik Schmid J, Schmid JP, Côte M, Ménager MM, Burgess A, Nehme N, Ménasché G, Fisher A, de Saint BG (2010) Inherited 
defects in lymphocyte cytotoxic activity. Immunol Rev 235(Suppl 1):10-23

33. Ritchie DS, Angus PW, Bhathal PS, Grigg AP (2002) Liver failure complicating non-alcoholic steatohepatitis following allogeneic bone marrow transplantation for Shwachman-Diamond syndrome. Bone Marrow Transplant 29(11):931-933

34. Rosendahl J, Teich N, Mossner J, Edelmann J, Koch CA (2006) Compound heterozygous mutations of the SBDS gene in a patient with Shwachman-Diamond syndrome, type 1 diabetes mellitus and osteoporosis. Pancreatology 6(Suppl 6):549-554

35. Savilahti E, Rapola J (1984) Frequent myocardial lesions in Shwachman's syndrome. Eight fatal cases among 16 Finnish patients. Acta Paediatr Scand 73(Suppl 5):642-651

36. Shwachman H, Diamond LK, Oski FA, Khaw KT (1964) The syndrome of pancreatic insufficiency and bone marrow dysfunction. J Pediatr 65:645-663
37. Toiviainen-Salo S, Durie PR, Numminen K, Heikkilä P, Marttinen E, Savilahti E, Mäkitie O (2009) The natural history of ShwachmanDiamond syndrome-associated liver disease from childhood to adulthood. J Pediatr 155(Suppl 6):807-811, e2

38. Toiviainen-Salo S, Mäkitie $\mathrm{O}$, Mannerkoski $\mathrm{M}$, Hämäläinen $\mathrm{J}$, Valanne L, Autti T (2008) Shwachman-Diamond syndrome is associated with structural brain alterations on MRI. Am J Med Genet 146A(Suppl 12):1558-1564

39. Toiviainen-Salo S, Mäyränpää $M K$, Durie PR, Richards N, Grynpas M, Ellis L, Ikegawa S, Cole WG, Rommens J, Marttinen E, Savilahti E, Mäkitie O (2007) Shwachman-Diamond syndrome is associated with low-turnover osteoporosis. Bone 41(Suppl 6):965972

40. Wilschanski M, van der Hoeven E, Phillips J, Shuckett B, Durie PR (1994) Shwachman-Diamond syndrome presenting as hepatosplenomegaly. J Pediatr Gastroenterol Nutr 19:111-113 